\title{
Phenotypic and genotypic detection of microcin produced by some Enterobacteraceae
}

\author{
Sahar Mohammed Jawad Hanan Fadhil Kadhum* \\ Department of Soil Science and Water Resources / Faculty of Agriculture / Kufa University \\ * Biology Department / Faculty of Education for Girls / Kufa University \\ E-mail: saharm.alkarawy@uokufa.edu.iq, hananf.aljabury@ uokufa.edu.iq
}

\begin{abstract}
Back ground: Microcins are ribosomal synthesized antimicrobial peptides produced principally by bacteria of the Enterobacteriaceae family that are active against other bacteria, either in the same species (narrow spectrum), or across genera (broad spectrum) that share the same ecological niche.
\end{abstract}

Objective: The ability of the Enterobacteriaceae to produce microsines.

Materials and methods: One hundred urine samples have been collected from patients suffering from UTI whom admitted to Al Hakim Hospital in AL-Najaf City during the period from 17October 2017 to 13 February 2018.

Results: The results of PCR technique for amplification show that all isolates were possess mic $\mathrm{N}$ by appearance of amplicon with molecular weight 938 bp while $46(76 \%)$ isolates were possess mic N1and 24 (40\%) isolates were possess mic $N 2$ gene by appearance of amplicon with molecular weight 368 bp and 167 bp respectively.Cross-streak activity assay was used to detect the selected strains with antibacterial activities against pathogenic bacteria.

Conclusion: some isolates have one or more gene microcin encoded of , however, microcin $\mathrm{N}$ is present in all isolates.

Keywords: Enterobacteriaceae, Microcin, PCR.

\section{Introduction}

The family Enterobacteriaceae comprises a large heterogeneous group of Gram-negative, although they are uncommonly found outside the gastrointestinal tract, they are a leading cause of nosocomial disease $(1,2)$. Enterobacteriaceae are wide world distributed, it might be found in, plants, soil ,water, humans and animals, because it is responsible for a broad range of infections in humans and animals. the main genera are Escherichia, Salmonella, Enterobacter, Citrobacter, Klebsiella, Shigella and Yersinia. Certain species are part of the normal flora of animals including humans, although many are frequently associated with diarrheal disease and extra intestinal infections.(3). Bacteria engender antimicrobial compounds to inhibit or kill other competing strains because they survive in the environment and their competition with other microorganisms for purse.(4) .This antimicrobial peptides are just one of the many classes of antimicrobial component, One of these peptides, microcin $\mathrm{N}$ are low-molecular-weight $\left(\begin{array}{lll}10 & 000 & \mathrm{Da}\end{array}\right)$ antimicrobial peptides secreted by members of the Enterobacteriaceae family and are associated in microbial competition inside the intestinal tract. Microcin, which is widely distributed in enterobacteria, is a small ribosomally-synthesized, powerful antimicrobial peptide against a wide range of Gram-negative and some Gram-positive bacteria. (5) As a hopeful antibiotic against antibiotic resistance, this study is aimed to determine the presence of gene encoding microcin $\mathrm{N}$ in Enterobacteriaceae isolated from patients suffering from UTI as well as phenotypic detection of microcin by Cross-streak activity assay.

\section{Methods}

\section{Sampling and Bacteria Isolation}

A total of 100 specimens were collected from patients with urinary tract infection of both sex with age group range from 20-55 years old whom admitted to Al Hakim Hospital during the period from 17 October 2017 to 13 February 2018. To identified bacterial isolates they were re-cultured on nutrient agar media for identification then each purified single colony was cultured on Chrom agar to certain identification of bacterial isolate. Urine samples 
were diluted with normal saline $(5 \mathrm{ml})$, then transferred by a sterile loop to Chrom agar media where they were streaked and incubated at $37^{\circ} \mathrm{C}$ for $24-48 \mathrm{hr}$ for isolation of Enterobacteriaceae .

Table (1): Identification of Bacterial Isolates on Chrom agar media

\begin{tabular}{l|c|c}
\hline \multirow{2}{*}{ Name of bacteria } & \multicolumn{2}{c}{ Result } \\
\cline { 2 - 3 } & Dark pink & $-\mathrm{Ve}$ \\
\hline E.coli & Metallic bule \\
Citrobacter & Metallic blue with red halo \\
Enterococcus & Turquoise bule \\
Staphylococcus aureus & Golden, opaque, small & no color \\
Staphylococcus saprophyticus & Pink, opaque, small \\
\hline
\end{tabular}

\section{DNA Extraction}

Boiling methods (TE buffer method) that described by (6) was carried out was carried out using the Template DNA that was prepared by dissolving $1 \mu 1$ of bacteria in $1 \mathrm{ml}$ of TE buffer, centrifuged at $5000 \mathrm{rpm}$ for $5 \mathrm{~min}$, and the pellet resuspended in $100 \mu \mathrm{l}$ of TE buffer. The suspension was boiled at $100 \mathrm{c}^{\circ}$ for $10 \mathrm{~min}$ before centrifugation at $5000 \mathrm{rpm}$ for $5 \mathrm{~min}$. The supernatant accommodated as PCR template. Extracted DNA was qualified by using $1.5 \%$ agarose gel electrophoresis.

\section{Preparation of Primer}

The sequences of oligonucleotide were mentioned in (Table 2). All primers that used in this study were prepared according to the recommendation of manufacture by dissolving lyophilized primer with a propriate TE buffer to yield $100 \mu \mathrm{M}$ of stock solution. Working solution was prepared by diluent with TE buffer to yield $1 \mu \mathrm{M}$ of each primer.

Table (2): The sequences of oligonucleotide, primer that used

\begin{tabular}{|c|c|c|c|}
\hline Genes & Primer sequence & $\begin{array}{c}\text { Size of } \\
\text { amplicon }\end{array}$ & \\
\hline $\operatorname{micN}$ & $\begin{array}{l}\text { F- TCGGAGCGATTATGGACAGC } \\
\text { R- TCTGGCACATTCCACCATCC }\end{array}$ & 983 & $\begin{array}{l}\text { Designed in } \\
\text { this study }\end{array}$ \\
\hline $\operatorname{mic} N-1$ & $\begin{array}{l}\text { F- TACGGCATTATCAGCCGGAC } \\
\text { R- TCAAGAGAACGACCACCTGC }\end{array}$ & 386 & \\
\hline $\operatorname{mic} N-2$ & $\begin{array}{l}\text { F- GAAAGCCAGATGCAGACCCT } \\
\text { R- CCCGGTGTAACACTCAACGA }\end{array}$ & 167 & \\
\hline
\end{tabular}

\section{Amplification Process}

Amplification reaction mixture was prepared with final volume $20 \mu \mathrm{l}$ by mixing all contents in Table (3) and Table (4), then centrifuged for short spin and transferred to thermo cycler, with the following thermal cycling conditions: 2 minutes at $94^{\circ} \mathrm{C}$ and 30 cycles of amplification consisting of 30 seconds at $94^{\circ} \mathrm{C}, 30$ seconds at $59^{\circ} \mathrm{C}$, and 60 seconds at $72^{\circ} \mathrm{C}$, with 5 minutes at $72^{\circ} \mathrm{C}$ for the final extension. PCR products were analyzed by electrophoresis on a $1 \%$ agarose gel at $70 \mathrm{~V}$ for 60 minutes. Gel documentation system was used for ritualization of amplicon bands. 
Table (3): The Mixture of Amplification Reaction

\begin{tabular}{c|c}
\hline Item & Volume $\boldsymbol{\mu l}$ \\
\hline PCR Master mix & 5 \\
Forword & 1 \\
Reverse & 1 \\
DNA template & 2 \\
Nuclease free water & 11 \\
Total volume & 20 \\
\hline
\end{tabular}

Table (4): The Amplification Condition

\begin{tabular}{|c|c|c|c|c|c|c|c|c|c|}
\hline تِّ & 苞 & 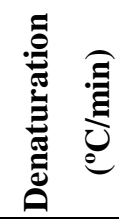 & 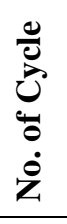 & 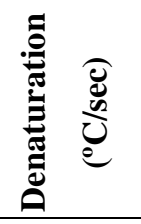 & 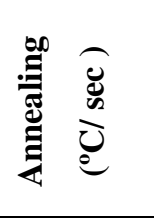 & 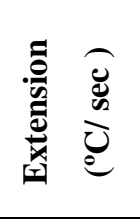 & 茎 & 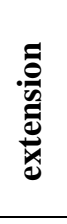 & ¿્ڤ \\
\hline $\operatorname{mic} N$ & & $95 / 2$ & 30 & $95 / 30$ & $59.3 / 30$ & $72 / 40$ & & $72 / 5$ & \\
\hline $\operatorname{mic} N 1$ & & $95 / 2$ & 30 & $95 / 30$ & $59.1 / 30$ & $72 / 100$ & & $72 / 5$ & \\
\hline $\operatorname{mic} N 2$ & & $95 / 2$ & 30 & $95 / 30$ & $59.3 / 30$ & $72 / 20$ & & $72 / 5$ & \\
\hline
\end{tabular}

\section{Phenotypic detection of microcin}

To evaluate the ability of all bacterial isolates to produce microcin, a method described by (7) was carried out with some modifications. M9 and M63 media were used to evaluated the efficiency of bacterial isolates to produce microcin. All bacterial isolates were streaked on M9 and M63 media as a width line in the middle of media and incubated for $24 \mathrm{hr}$. at $37^{\circ} \mathrm{C}$. At the terminus of incubation period, the densely overgrown streak was chloroforminactivated utilizing pipette covering the whole streak of bacteria by thin film of chlorophorm. The inhibitory activity was tenacious qualitatively by applying $10 \mu \mathrm{l}$ of a standardized $0.9 \% \mathrm{NaCl}$ suspension of tested microcin that engendered from isolate. A result was defined to be positive if an inhibition zone was present on both side of the engendering strain and inhibitory activities were visually relegated as vigorous, clear and visible.

\section{Detection the activity of purified microcin}

The activity of purified microcin was detected with one exception that the growth of bacterial isolate were replaced by microcin $(0.5 \mathrm{gm} / \mathrm{ml})$ which streak on the surface of M63 medium and pathogenic isolate were streak vertically on microcin, then the plate were cultured at $37^{\circ} \mathrm{C}$ for $24 \mathrm{hr}$. The appearance of inhibition zone referred to activity of microcin.(8).

\section{Purification of microcin}

Microcin purification method was carried out as described by (9). 


\section{Results and Discussion}

The result of isolation and identification of Enterobacteriaceae members on CHROM Agar showed a wide distribution of Enterobacteriaceae members among all collected sample in which all 100 (100\%) sample gave +ve culture .

Enterobacteriaceae, reported by (10) were recovered from pus samples $44.19 \%$, followed by urine $36.05 \%$ and blood $8.14 \%$ (6) showed that $46.1 \%$ Enterobacteriaceae from patients with diarrhea, $42.3 \%$ animals and insects. (11) collected from faecal samples of inpatients. A number of studies have been confirmed Enterobacteriaceae bacteremia most commonly occurred in patients with malignancies $48.9 \%$ or hepatobiliary stones $22.2 \%$.

The percentage of isolation of Enterobacteriaceae species was as followed: $48 \%$ (48 isolate) of E. coli ; $32 \%$ (32 isolate) of Klebsiella ; Citrobacter isolates 9 (9\%); 11\% (11 isolate) of Enterobacer.

Microcin antibiotic like structure which produced by a member of Enterobacteriaceae and promising antibacterial activity against antibiotic resistance bacteria and other closely related microorganism (12).The result showed that the minimal M9 and M63 were more efficient in enhancement of bacterial isolate to produce microcin in which a large inhibition zone (Figure 1).

Other studies showed that microcin may be produced during stationary phase except microcin E492 which produced during exponential phase (13). In the present study we found that microcin was produce during stationary phase (after $24 \mathrm{hr}$ of incubation). This variation in the time of production may correlated with the structure of microcin which is a thermo stable peptides protease resistance and resistance to extreme PH (14). Many studies showed that the activity of microcin correlated with the structure of outer membrane of bacterial cells (a target for microcin activity).(15, 16).

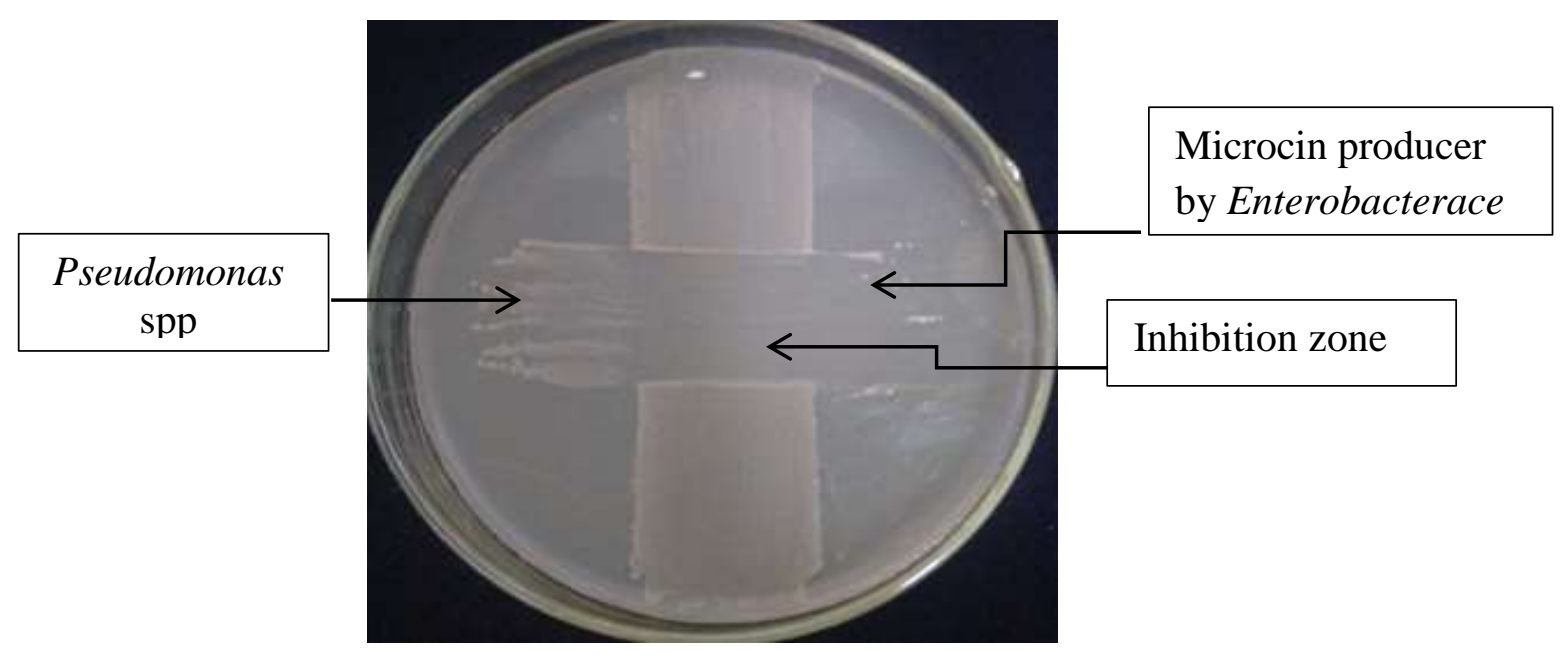

Figure (1): inhibitory activity of pathogenic bacteria (Pseudomonas) microcin against Enterobacterace, measured with the cross-streak activity assay

In this study, microcin N gene from Enterobacteriaceae was screened by using PCR in 100 clinical specimens of patients. Sequencing confirmed the fidelity of amplicon. Results showed a high prevalence of Enterobacteriaceae strains harboring this gene, which can be an explanation of these bacteria being a common microbial flora in some of AL-najaf hospital. More experiments and research in the For example, the study was done by (4) the effect of microcin produced by Enterobacteriaceae on E. coli in a co-culture condition confirmed the sensitivity of Escherichia coli to microcin (17). Hindered isolate clinical specimens were collected from urinary tract infection and were selected for genotypic detection of gene coding for microcin. These isolate were selected on its microcin activity and site of isolation. The results of agarose gel electrophoresis rises of amplicon showed that all isolate 
were possess mic $\mathrm{N}$ by appearance of amplicon with molecular weight 938 bp while 33 (33\%) isolates were possess mic Nland 21 (21\%) isolates were possess mic N2 gene by appearance of amplicon with molecular weight $368 \mathrm{bp}$ and 167 bp respectively (Figure 2,3,4). because of the high importance of microcin $\mathrm{N}$ in medicine, we focused on its prevalence in bacteria isolated from hospitals. Past and ongoing researches on antimicrobial peptides have shown that these compounds have a great potential to be used in food and medical industries. Discoveries of new antimicrobial peptides and the understanding of the biological process involved in the synthesis, immunity, and regulation of antimicrobial peptides, should play a role in this field, with emphasis on practical applications in the industry (3).

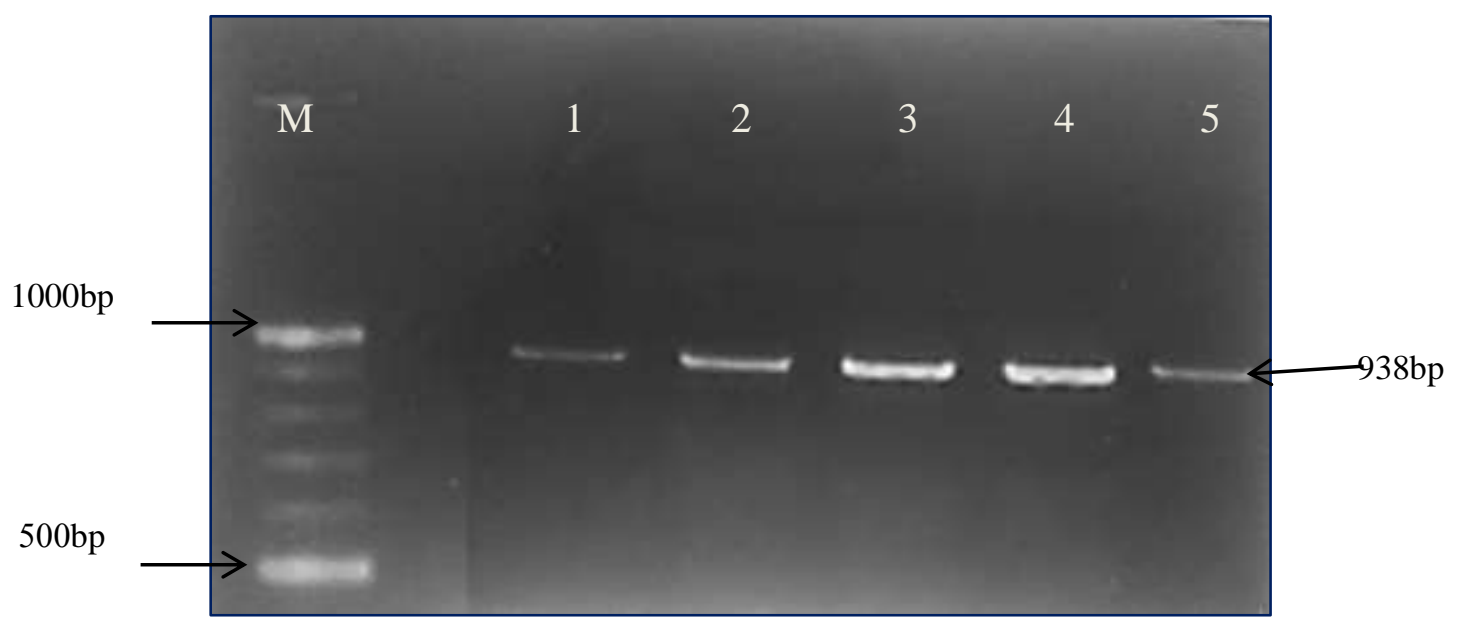

Figure (2): Agarose gel electrophoresis (1\% at 70 volt $60 \mathrm{~min})$ of amplicon resulted from amplification of mic N (938 bp). Lane L:DNA, Marker ( 1000 bp) lane $(1,2,3,4,5)$ positive to for amplification

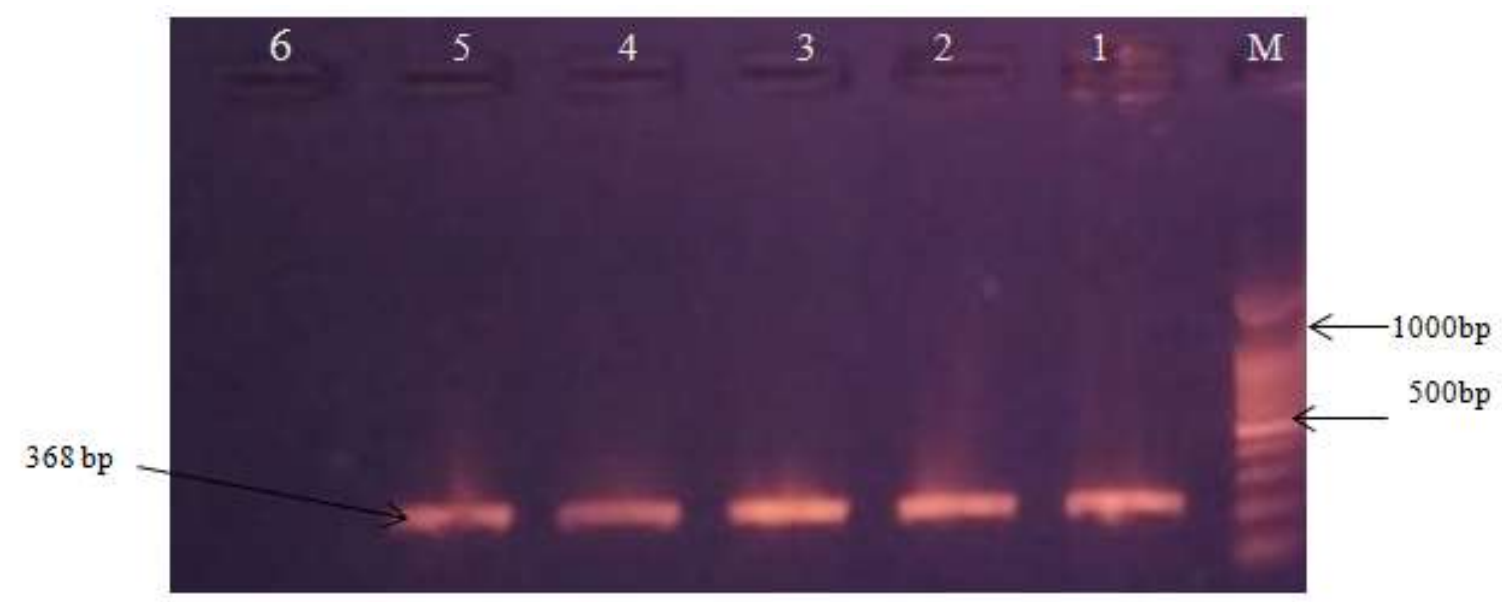

Figure (3): Agarose gel electrophoresis (1\% at 70 volt $60 \mathrm{~min}$ ) of amplicon resulted from amplification of mic N1 (368 bp). Lane L:DNA, Marker ( 1000 bp) lane $(1,2,3,4,5)$ positive to for amplification, Lane (6) negative for amplification 


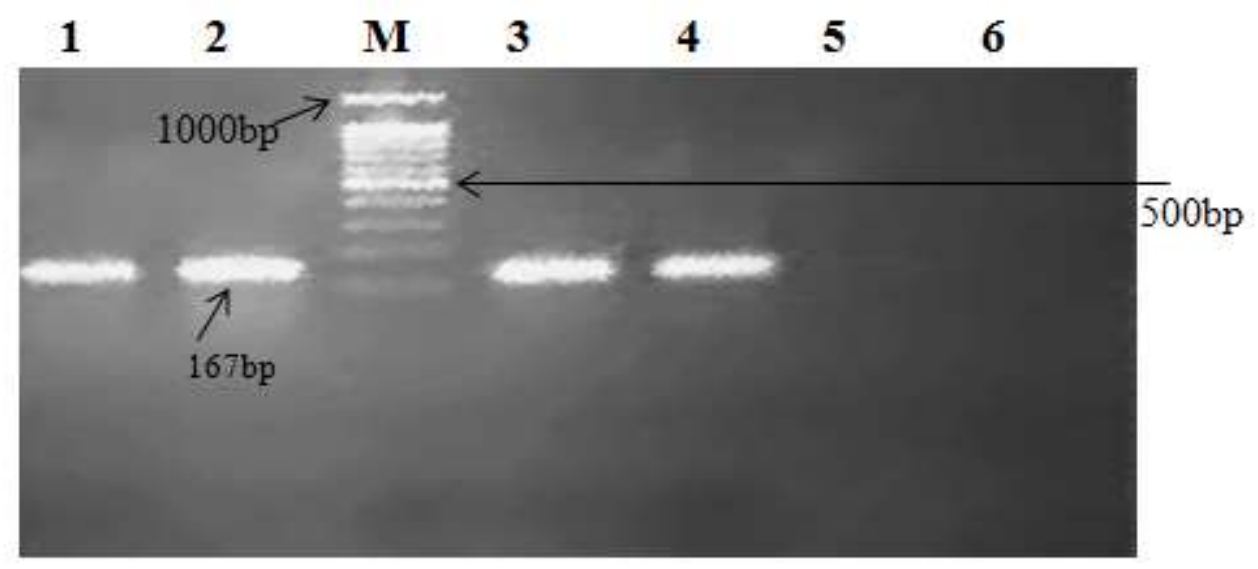

Figure (4): Agarose gel electrophoresis (1\% at 70 volt $60 \mathrm{~min}$ ) of amplicon resulted from amplification of mic N2 (167 bp). Lane L:DNA, Marker (1000 bp) lane $(1,2,3,4)$ positive to for amplification, Lane $(5,6)$, negative for amplification

\section{Conclusions}

1- Microcin was detected by molecular technique, it is showed that some isolates have one or more gene microcin encoded of, however, microcin $\mathrm{N}$ is present in all isolates.

2- Microcin production is seen when minimal media M63 is used.

3- All isolates showed high ability to activity against pathogenic isolate.

\section{Reference}

1. Ryan, Kenneth J, M.D. Madical microbiology, New York. LCCQR46.(2018); 7:343-344.

2. Holt KE, Wertheim H, Zadoks RN, Baker S, Whitehouse CA, Dance D. Genomic analysis of diversity, population structure, virulence, and antimicrobial resistance in Klebsiella pneumoniae, an urgent threat to public health. Proc Natl Acad Sci USA. (2015); 112 (27): 3574-81.

3. Rosell J, Barragán A, Carbonell MD. Septicaemia caused by Citrobacter braakii infection in a captive Nile crocodile (Crocodylus niloticus). J Comp Pathol.(2017); 156 (1):105.

4. De Lorenzo V, Pugsley AP. Microcin E492. a low-molecular-weight peptide antibiotic which causes depolarization of the Escherichia coli cytoplasmic membrane. Antimicrob Agents Chemother. (1985);27(4):666-9.

5. Gulluce M, Karaday M, Barıs O . Bacteriocins: Promising Natural Antimicrobials. science, technology and education. (2013); 1016-27.

6. Klingenberg C ,Sundsfjord A, Rønnestad A, Mikalsen J, Gaustad P, Flaegstad T. Phenotypic and genotypic aminoglycoside resistance in blood culture isolates of coagulase-negative staphylococci from a single neonatal intensive care unit,1989-2000. J.Antimicrob.Chemother. (2004);6(54): 889-896.

7. Pugsley A, Nucleotide sequencing of the structural gene for colicin $\mathrm{N}$ reveals homology between the catalytic, C-terminal domains of colicins A and N. Molecular Microbiology. (1987); 1(5): 317-325.

8. Arranz R, Mercado G, Martin-Benito J, Giraldo R, Monasterio O, Lagos R, et al. Structural characterization of microcin E492 amyloid formation: Identification of the precursors. J Struct Biol. (2012);178(1):54-60.

9. Iuliia Piskunova . Maturation and Functional Analysis of Microcin C-Like Compounds. Doctoral Thesis, Moscow. (2017). 
10. Ali AM, Rafi S, Qureshi AM. Frequency of ESBL producing gram negative bacilli among the clinical isolates at the clinical laboratories of the Army Medical College, Rawalpindi. J. of Ayub Medical College. (2004); 16 (1): $1-3$.

11. Mohammad Shahnawaz, Kyung-Won Park, Abhisek Mukherjee, Rodrigo Diaz-Espinoza, Claudio Soto. Prionlike characteristics of the bacterial protein Microcin E492. Scientific Reports. (2017); 7(2):45-50.

12. Brisse S, Grimont F, Grimont PAD. The genus Klebsiella. Prokaryotes. J. of Ayub Medical College. (2006);6(8):159-96.

13. Alves MS, Dias RC, de Castro AC, Riley LW, Moreira BM. Identification of clinical isolates of indole-positive and indole-negative Klebsiella spp. J Clin Microbiol. (2006);44(10):3640-6.

14. De Lorenzo V, Martinez J L, Asensio C. Microcin-mediated interactions between Klebsiella pneumoniae and Escherichia coli strains. J Gen Microbiol. (1984);130(2):391- 400.

15. Golshani Z, Ahadi AM,Sharifzade A.Occurrence of ambler class b metallo- $\beta$-lactamase gene in imipenemresistant pseudomonas aeruginosa strains isolated from clinical clinical specimens. J Res Med Sci.(2014);16(2):69.

16. Edgar RC. MUSCLE: multiple sequence alignment with high accuracy and high throughput. Nucleic Acids Res. (2004);32(5):1792-7.

17. De Padua SB, Marques DP, Sebastiao FA, Pilarski F, Martins ML, Ishikawa MM. Isolation, characterization and pathology of Citrobacter freundii infection in native Brazilian catfish Pseudoplatystoma. Braz. J. Vet. Pathol. (2014);7 (9): 151-157. 